\section{EDUCATION}

Research, Innovation and Solutions on-line ${ }^{(0)}$
Electronic Journal of Research

in Educational Psychology

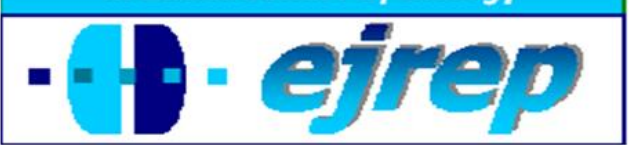

\title{
Exam Preparation: The Influence of Action Control, Procrastination and Examination Experience on Students' Goal Intention and Implementation Intention
}

\author{
Lutz Sommer $^{1}$ \\ ${ }^{1}$ Department of Business Administration and Engineering, Albstadt- \\ Sigmairngen University, Albstadt
}

\section{Germany}

Correspondence: Lutz. Sommer. Jakobstraße 1-6, 72458 Albstadt, Germany. E-mail: sommer@ hs-albsig.de

(C) Education \& Psychology I+D+i and Editorial EOS (Spain) 


\section{Abstract}

Introduction. In the framework of the intention-behavior-gap analysis in relation to exam preparation I examined whether intention - subdivided into goal and implementation intention - is influenced directly by the determinants action control, procrastination and examination experience which is inconsistent with the Theory of Planned Behavior and whether their influence varies in its intensity.

Method. Basis for the research was a survey $(\mathrm{N}=204)$ which investigated university students' (research participants) exam revision. In 2010, 1,149 German engineering students with an average age of 22.5 years received written questionnaires. 204 students were included in the overall evaluation. I used a structural equation modeling path analysis method to examine the possible relations between the above mentioned variables.

Results. The results show that the determinant examination experience has a significant and substantial influence on implementation intention, whereas goal intention hasn't. This influence is also relevant with regard to the determinant procrastination.

Discussion. Based on the results, that examination experience influences students'exam revision more than expected by the Theory of Planned Behavior model. I concluded that more examination experience could be an opportunity to reduce the intention-behavior-gap. Furthermore, it could be stated that the development of implementation intention is promoted by goal intention and examination experience. A unilateral focus on goal intention is not reasonable. Examination experience can have a positive impact on procrastination behavior. In addition, it could be stated, that a lack or lower level of methodological skills or examination experience can be decisive for study success. With regard to the determinant action control no influence was detected.

Keywords: Experience; Examination; Procrastination; Action Control; Intention; Students 


\title{
Preparación de exámenes: La influencia del control de ac- ción, la procrastinación y la experiencia con exámenes so- bre la intención de metas de los estudiantes y su intención de implementación
}

\begin{abstract}
Resumen
Introducción. En el marco del análisis de intención de comportamiento de diferencia en relación con la preparación de exámenes, se examinó si la intención - subdividida en objetivo y la intención puesta en práctica - está influenciada directamente por el control de la acción determinantes, la dilación y la experiencia de examen, que es incompatible con la Teoría del Comportamiento Planificado, y si su influencia varía en su intensidad .

Método. La base para la investigación fue un estudio ( $\mathrm{N}=204$ ), que investigó los universitarios ( participantes en la investigación ) la revisión del examen. En 2010, 1.149 estudiantes de ingeniería alemana, con una edad media de 22,5 años de edad recibieron cuestionarios escritos. Un total de 204 se incluyeron en la evaluación global. Se ha utilizado un método de análisis de la trayectoria de modelado de ecuaciones estructurales para analizar las posibles relaciones entre las variables mencionadas.
\end{abstract}

Resultados. Los resultados muestran que la experiencia de examen determinante tiene una influencia significativa y sustancial en la intención de la aplicación, mientras que la intención meta no tiene. Esta influencia también es relevante en cuanto a determinación de la dilación.

Discusión. En base a los resultados, que influye en la experiencia de examen de los estudianets, se debería realizar una revisión amplia de la teoría del modelo de comportamiento planificado . Se llega a la conclusión de que la experiencia de examen podría ser más una oportunidad para reducir la intención que de planificación de conducta . Además, se podría decir que el desarrollo de la intención de la aplicación es promovido por la intención de meta que por la experiencia de examen . Un enfoque unilateral sobre la intención meta no es razonable. La experiencia de examen puede tener un impacto positivo en el comportamiento de la dilación. Además, la falta o menor nivel de habilidades metodológicas o experiencia de examen pueden ser decisivos para el éxito del estudio. Con respecto a la acción determinante de control no se detectó ninguna influencia.

Palabras clave: Experiencia, Examen, dilación, Acción de Control, Intención, estudiantes. 


\section{Introduction}

An important research question in the context of human behavior deals with the intention-behavior-gap / intention-behavior-discrepancy, in other words: why is there a substantial gap between intention and actual behavior (Ajzen, 2005). Numerous scientific publications have dealt with this question with regard to different contexts. According to Ajzen (2005) possible reasons for this gap are: a) intention-behavior incompatibility, b) stability of intentions, c) literal inconsistency. The latter aspect, for example, investigates why people say one thing and do something else (Ajzen, 2005). In the context of this research question the Theory of Reasoned Action (TRA) by Fishbein and Ajzen (1975) and the Theory of Planned Behavior (TPB) by Ajzen $(1985,1991)$ are in the center of attention (Ajzen, 2005). Even though these theories, as approved by a number of surveys, are able to make a relevant contribution to close the intention-behavior-gap there remains a relevant gap that is independent from the context in question (Ajzen, 2005).

\section{Current state of research - intention-behavior-gap}

As the latest publications of Rhodes and Dickau (2012), de Bruin et al. (2012) and Mannetti, Pierro, Higgins and Kruglanski (2012) show, the issue is still topical. In various surveys concerning the above mentioned gap several moderators and determinants, respectively, are mentioned repeatedly. For example the authors van Hooft, Born, Taris, van der Flier and Blonk (2005) stated that action control (Kuhl, 1981, 1982) and action control theory according to Kuhl and Beckmann (1985), procrastination according to Lay (1986) and implementation intention according to Gollwitzer $(1993,1999)$ are maybe relevant to bridge the gap (van Hooft et al., 2005). This list has to be supplemented amongst other things by experience as frequently mentioned TPB construct. The study by van Hooft et al. (2005) on action control, procrastination and implementation concerning their relevance for the intentionbehavior-gap figured out that "support was found for the proposed mediating role of implementation intentions in the relation between job research intention and job research behavior. The proposed moderating roles of action-state orientation and trait procrastination were not supported" (van Hooft et al, 2005, p. 238). Literature includes both, publications that confirm the issue and such that discard it. To sum up, I would like to say that there are numerous studies dealing with the intention-behavior-gap. 


\section{Special context - Higher Education}

However, there is need for further research with regard to the context "higher education and exam revision". For example, there exist several recommendations in the field of higher education concerning the issue how to overcome procrastination behavior focusing on awareness, time management and motivation (Princeton University, 2012). Montalvo and Torres (2004) argue with regard to self-regulated learning: "strategic learner is one who has learned to plan, control and evaluate his or her cognitive, motivational/affective ... processes" (Montalvo and Torres, 2004, p. 22). However, a consistent examination of a possible relation between procrastination, examination experience (EE) and action control from the perspective of goal and implementation intention according to Gollwitzer (1999) remains undone.

The objective of this study is to examine the behavior of university students when preparing for exams, focusing on experience. I decided to examine to what extent experience influences the goal and implementation intention in terms of exam revision and which role action control and procrastination play in this context. In the following, I will present the relevant scientific foundations concerning action control, procrastination, implementation intention and experience and, based on this, I will develop the hypotheses.

\section{Action Control}

Action control according to Kuhl $(1981,1982)$ or Action Control Theory according to Kuhl and Beckmann (1985), respectively, is based on the differentiation between action and state orientation (Kuhl, 1994; van Hooft et al., 2005). According to Kuhl (1981, 1982), the following constructs can be formed "prospective (HOP) and failure-related (HOM) actionorientation" (Brunstein, 2001, p. 3). The author further explains that "while HOP deals with the accelerated versus hesitant implementation of intended actions, HOM deals with the weak versus strong disposition to constant brooding and sorrowful thoughts" (Brunstein, 2001, p. 3). Thus, it is possible that persons have the ability to rid themselves of "negative states of affect" (= HOM) or to induce "positive affects", which promotes the implementation of actions (Brunstein, 2001, p. 3).

Research concerning the action-state orientation delivered quite divergent results, e.g. Bagozzi and Baumgartner (1992) stated in their analysis that "state versus action orientation moderates the relative importance of determinants of intentions“ (p. 505), which can be regarded as a confirmation. Brunstein's (2001) study represents an additional confirmation of 
the action-state-orientation. In contrast, Norman, Sheeran and Orbell (2003) point out that particularly with regard to the intention-behavior-relationship, state or action orientation, respectively, has no moderating effect "between subjects and within-subjects analyses both failed to provide support for the moderating role of state vs. action orientation" (Norman, Sheeran and Orbell, 2003, p. 536). Other authors come to a similar conclusion that "the proposed moderating roles of action-state orientation ... were not supported" (van Hooft et al., 2005, p. 238). These two assessments are contradictory to the study by Sniehotta, Nagy, Scholz and Schwarzer (2006) who stated that "action control may be a promising construct to narrow the intention-behavior gap" (p. 87), which indicates that there is need for further research with regard to the relevance of the action-state orientation.

\section{Procrastination}

The second potentially relevant moderator, procrastination, deals with the human behavior pattern to postpone important activities in favor of usually much less important activities (Rist, Engberding, Patzelt \& Beißner, 2006), in other words: to procrastinate. Dewitte and Schouwenburg (2002) define procrastination as "a behavioural tendency with potentially damaging consequences for the person... because of their tendency to start late, procrastinators do not have enough time to perform at the level their capacities allow" (Ferrari, Johnson, \& McCown, 1995, p.470), whereas other authors only partly coincide with this definition. Lay (1986) subdivided procrastinators into optimistic and pessimistic procrastinators and Chu and Choi (2005) into passive and active procrastinators. Procrastination is generally considered to be negative,however, there are opposed studies, who demand rethinking because "the present results showed that although active procrastinators procrastinate to the same degree as passive procrastinators, they are more similar to non-procrastinators than to passive procrastinators" (Chu \& Choi, 2005, p. 245). I will follow the majority opinion stating that procrastination has a negative influence with regard to the implementation/transfer of intention into behavior.

As I have previously discussed (Sommer \& Haug, 2012), Gollwitzer (1993, 1999) introduced the term implementation intention, subdividing intention into goal intention and implementation intention. While goal intention describes an objective that shall be achieved, implementation intention serves as specification for the implementation of the objective (Gollwitzer, 1999). Thus, implementation intention is typically positioned downstream of goal intention (Gollwitzer, 1999). Summing up, Gollwitzer (1999) concluded "Implementa- 
tion Intentions delegate the control of goal-directed responses to anticipated situational cues, which ... elicit these responses automatically" (p. 493), and confirmed in 2001 as a co-author this basic statement in a downstream study (Brandstätter, Lengfelder \& Gollwitzer, 2001). He concluded that in relevant situations persons with implementation intention in fact implemented goal-directed behavior more effectively and faster than persons without implementation intention (Brandstätter, Lengfelder \& Gollwitzer, 2001, pp. 946 et seqq.).

Another study by the above mentioned author deals with the question "whether people's goal intentions moderate automatic action initiation by implementation intention" (Sheeran, Webb \& Gollwitzer, 2005, p. 88; Sheeran, Orbell \& Trafimow, 1999). Here, too, the authors come to a positive assessment. In another study with Gollwitzer as a co-author, published in 2011, the relevance of implementation intention is documented insofar as the authors concluded that even habits can be overcome: "that formulating counterhabitual implementation intentions increases individuals' flexibility to choose which behavior to perform in the critical situation" (Adriaanse, Gollwitzer, Ridder \& de Wit, 2011, p. 502).

\section{Theory of Planned Behavior - Implementation Intention and Experience}

However, the discussion about intention and behavior cannot be led without taking into account the Theory of Planned Behavior (TPB). Ajzen (2005) explains that the relation between intention and behavior is illustrated by a model that uses the constructs attitudes (ATT), social norm (SN) and perceived behavioral control (PBC) to predict intention (Ajzen, 2005).

As I have previously discussed (e.g. Sommer, 2011; Sommer \& Haug, 2012), two aspects are included implicitly in the TPB model that could contribute to reducing the intentionbehavior gap: (1) On the one hand, there is implementation intention, as discussed above, provided that intention is subdivided into goal intention and implementation intention, as proposed by Gollwitzer (1999); (2) On the other hand, there is experience which in the model above only has the influence of a background factor (Ajzen, 2005). Implementation intention as an approach to reduce the gap was examined by Ajzen (2005) for example in connection with literal inconsistencies: "perhaps consistent with this account, implementation intentions may be effective because they improve memory for the behavioral intention" (Ajzen, 2005, p. 106). However, he relativizes this approval concerning the relevance of implementation intention "alternatively, it is possible to attribute the effectiveness of implementation intentions to 
a sense of commitment they engender" (Ajzen, 2005, p. 106). In other words: the author requires further research with regard to possible mechanisms in connection with implementation intention and behavior. As mentioned before: Experiences could be seen as the other potential influencing factor. This is a frequently discussed influencing factor in connection with the TPB model, which again and again, or still, is the subject of scientific discussion. The question is whether experience or past behavior directly influences intention or whether it is merely a background factor, and takes effect indirectly. There are a number of studies that assume a more or less strong influence of experience or past behavior or habits with regard to intention (Sommer, 2011; Sommer \& Haug, 2012). Current studies like the one by Coté, Gagon, Kouffé Houme, Abdeljelil and Gagon (2012), too, confirm the relevance of past behavior. However, these studies are in conflict with numerous oppositional studies that notably question the relevance of past behavior and/or experience (Sommer, 2011; Sommer \& Haug, 2012). In the context of the TPB model experience is classified explicitly as background factor (Ajzen, 2005). Ajzen (2005) postulates unambiguously that experience has no direct influence on intention but merely an indirect influence via beliefs and thus via the determinants ATT, SN and PBC (Ajzen, 2005). However, examining the discussion concerning experience over the last few years it becomes obvious that there are already significant differences when it comes to the definition of the term in itself. Some authors use the term past behavior, others the term past experience (Sommer, 2011; Sommer \& Haug, 2012). Therefore, I will use an online dictionary definition for experience that is globally accepted: "Experience ... (the process of getting) knowledge or skill from doing, seeing or feeling things ...something that happens to you that affects how you feel" (Cambridge University, 2012). According to this, at least two components are relevant parts of experience: "knowledge/skills" gained through activities in the past and "feelings" in connection with activities in the past (Cambridge University, 2012). The relevance of examination experience could be also seen by the results of Clariana, Gotzens, Badia and Cladellas (2012). The authors argue "that sutdents have learned to procrastinate and cheat" (Clariana, Gotzens, Badia, \& Cladellas, 2012, p. 750). Therefore, both components are part of the examination below.

\section{Objectives and hypotheses}

On the basis of the above statements, I established several hypotheses. Based on a preceding study that examined the additional influence of experience and procrastination on implementation intention taking into account the TPB conform constructs ATT, SN and PBC (Sommer \& Haug, 2012), I will now examine the influence of experience, procrastination and 
action control on implementation intention and on goal intention exclusively without taking into account the other TPB-constructs. This approach partly follows the study by van Hooft et al. (2005), who, too, examined goal intention and implementation intention. However, in contrast to van Hooft et al. (2005) this paper doesn't examine behavior. This is due to the fact that the focus of this paper is on the intention part of the intention-behavior gap. It has to be clarified if goal intention and/or implementation intention are influenced by the non-TPB conform determinants action control, procrastination and experience and if the intensity of this influence varies according to the type of intention. In contrast to van Hooft et al. (2005) I didn't regard the TPB conform constructs ATT, SN and PBC. University students' exam revision was chosen as thematic context.

The first hypothesis examines, if experience in the sense of "knowledge/skills" has a positive influence on goal and implementation intention, as I have partly discussed in a former article (Sommer \& Haug, 2012): H1. There is a positive, significant influence of experience in the sense of "knowledge/skills" on goal and implementation intention in terms of university students ${ }^{6}$ exam revision. This influence can be described by an approvable, significant structural equation model.

The second hypothesis examines the possible influence of action control according to Kuhl $(1981,1982,1994)$ on goal and implementation intention. The objective is the verification of this influence that is controversially discussed in literature: H.2. There is a positive, significant influence of goal and implementation intention through action control in terms of university students' exam revision. This influence can be described by an approvable, significant structural equation model.

Both research models can be illustrated by the figure below:

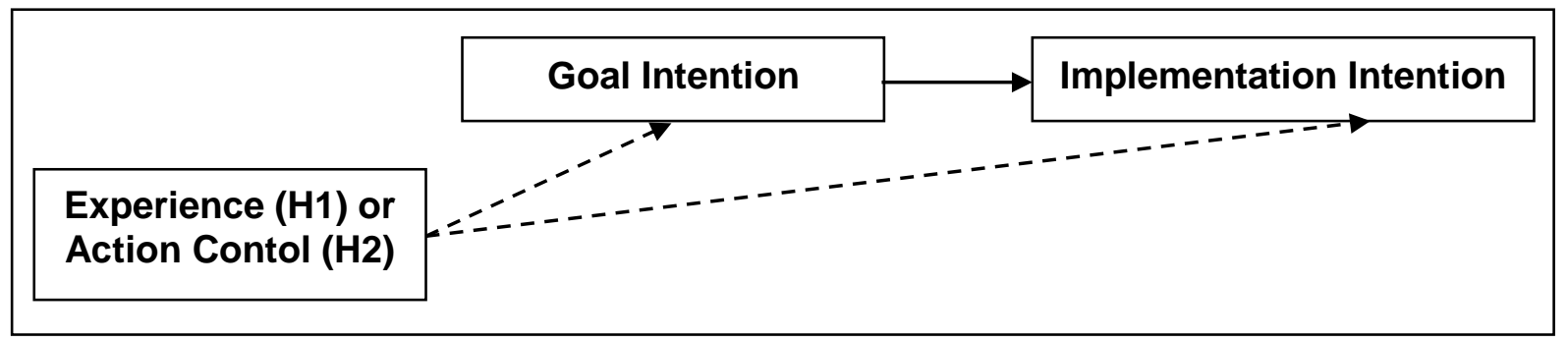

Figure 1. Research Model with Hypothesis $\mathrm{H1}$ and $\mathrm{H2}$ 
The third hypothesis examines the influence of procrastination. There are similarities between experience and procrastination - as defined by the University of Cambridge (2012) due to the fact that former examination experience on the basis of "knowledge/skills" and "feelings" was used to create the construct procrastination. In other words: procrastination could influence as a moderator the relation between experience and goal and/or implementation intention. H3. There is a positive, significant influence of experience in the sense of "knowledge/skills" - moderated by procrastination - on goal and implementation intention in terms of university students' exam revision. This influence can be described by an approvable, significant structural equation model.

In summary, I illustrate the hypotheses by the following research model:

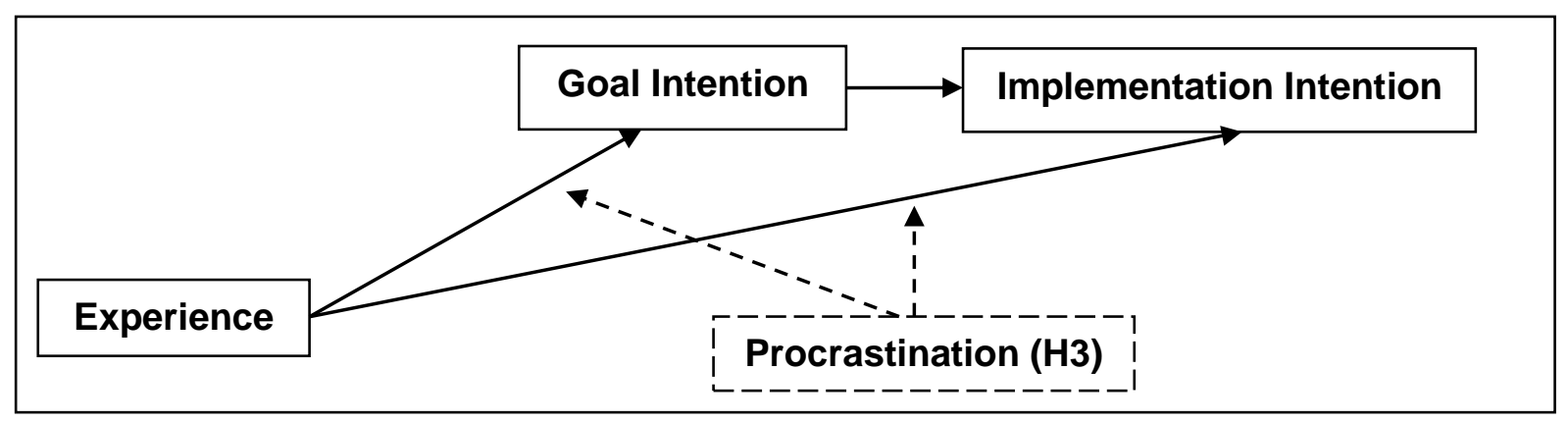

Figure 2. Research Model with Hypothesis H3

\section{Method}

For the survey I used an empirical data collection of the Albstadt-Sigmaringen University, Germany, dating from the year 2010 (Sommer, 2010). The data set at hand has already been analyzed in the framework of a previous article with regard to the Theory of Planned Behavior and the influence of experience and procrastination on implementation intention (Sommer \& Haug, 2012). This forerunner study pointed out that the constructs attitude, social norm and perceived behavioral control, as expected by Ajzen (2005), had a positive influence on goal intention (GI). In addition, the authors found evidence for a positive correlation between goal and implementation intention and gathered knowledge about the relation between examination experience and implementation intention / procrastination (Sommer \& Haug, 2012, pp. 46 et seqq.). 
For the present study, I reanalyzed and revised the existing data set. Furthermore, additional data that were not used so far were integrated for the new examination focus. The study is based on the following methodical approach (Sommer \& Haug, 2012).

\section{Participants}

The random sample is based upon a survey conducted among 1,149 students of the Faculty of Engineering of the Albstadt-Sigmaringen University, Germany, who received a questionnaire concerning the subject "exam revision". The students were informed that participation in the survey was optional. I offered no financial benefits or other incentives. 239 out of 1,149 students filled in the questionnaire. The additional part concerning "state and action orientation" that hasn't been evaluated before was filled in by 211 students. 204 questionnaires with completed additional part are included in the overall evaluation. 80 percent of these returns came from male participants with an average age of 22.5 years. Approximately 64 percent of the participants had a general university entrance qualification (equivalent to Alevels in the UK)(cf. Sommer \& Haug, 2012).

\section{Instruments and procedure}

As instrument a written questionnaire was used. The questionnaire had to be filled in in writing and could be handed in via lockbox. It includes 5 general and 35 specific items and is subdivided into three parts. The first part consists of personal questions and questions concerning context-related experience. Items 4 and 5 examine school education and serve as a benchmark for the level of examination experience. The more sophisticated the education the higher the level of examination experience. According to item 4, for example, the experience of students with the highest possible school education (A-level) obtains the highest value on an ordinal scale. Item 5 evaluates the type of school. German students from secondary schools providing general education have more studies-relevant examination experience than students from vocational schools, who benefit from an abbreviation of school education due to acknowledgement of their vocational training. Therefore, students from secondary schools providing general education achieve a higher value on an ordinal scale. Items 6 to 8 were not relevant for the paper at hand. The second part of the questionnaire includes questions concerning intention and the Theory of Planned Behavior (TPB). The third part includes questions concerning procrastination on the basis of the procrastination scale by Aitken (1982) and a version based on Rist et al. (2006) in a translated form. The 19 items were in parts recoded (Aitken, 1982; Rist et al., 2006), aggregated to cumulative values and then evaluated. Addi- 
tionally, there is a general part at the end of the questionnaire that could be filled in by persons who wanted to know if they are rather state-oriented or action-oriented persons as defined by Kuhl $(1981,1982,1994)$. An abbreviated version of the questionnaire is in the appendices of the paper at hand (cf. Sommer \& Haug, 2012)

The table below gives an overview of the structure of the questionnaire (Sommer \& Haug, 2012):

Table 1. Overview of the Structure of the Questionnaire

\begin{tabular}{|c|c|c|c|c|c|}
\hline $\begin{array}{l}\text { Question } \\
\text { Numbers }\end{array}$ & Item Name & $\begin{array}{l}\text { Construct } \\
\text { Name }\end{array}$ & $\begin{array}{l}\text { Construct } \\
\text { Measured }\end{array}$ & Scale & Source \\
\hline $1-3$ & Item 1 - 3 & - & $\begin{array}{l}\text { General Ques- } \\
\text { tions }\end{array}$ & diverse & - \\
\hline $4-8$ & Item 4 - 8 & $\mathrm{EE}$ & $\begin{array}{l}\text { Examination } \\
\text { Experience }\end{array}$ & diverse & - \\
\hline 9,12 & Item 9, 12 & GI & Goal Intention & $1-5$ & Gollwitzer (1993) \\
\hline $10,11,13$ & Item $10,11,13$ & I I & $\begin{array}{l}\text { Implementation } \\
\text { Intention }\end{array}$ & $1-5$ & $\begin{array}{c}\text { Gollwitzer (1993); Hrisos } \\
\text { et al. (2008); Gollwitzer } \\
\text { (1999) }\end{array}$ \\
\hline $14-21$ & Item $14-21$ & $\begin{array}{l}\text { ATT, SN, } \\
\text { PBC }\end{array}$ & $\begin{array}{c}\text { TPB- } \\
\text { Determinants }\end{array}$ & $1-5$ & $\begin{array}{l}\text { Sheeran et al. (2005); } \\
\text { Rhodes \& Courneya } \\
\text { (2003); Rhodes et al. } \\
\text { (2006); Gollwitzer (1999); } \\
\text { Hrisos et al (2008); } \\
\text { Ajzen (2005) }\end{array}$ \\
\hline $22-40$ & Item $22-40$ & PRO & Procrastination & $1-5$ & $\begin{array}{c}\text { Aitken (1982); Rist et al } \\
\text { (2006) }\end{array}$ \\
\hline
\end{tabular}

The additional part of the questionnaire for the assessment of the state or action orientation of the participants is focused on the HOM and HOP scale as defined by Kuhl (1981, 1982, 1994). The HOM part (= action orientation after failure experience) consists of 12 questions; the HOP part (= degree of decision making and action planning) consists of 12 questions, too (Universität Zürich, 2010). These questions were taken from the abbreviated instructions for the HAKEMP 90 questionnaire (Universität Zürich, 2010). The HOM and HOP-related questions were adapted to the specific exam revision context and measure students' experience in this field. Details of the adaption are to be found in the appendices of the paper at hand. The 12 questions for the determination of the HOM and HOP orientation, respectively, were aggregated into one item each (= HOM item and HOP item) and then evalu- 
ated (Universität Zürich, 2010). So, I used items 1 to 13, items 22 to 41 and a modified version of the HOM and HOP part as defined by Kuhl (1981, 1982, 1994) (cf. Sommer \& Haug, 2012).

\section{Design and data analysis}

I carried out the evaluation by using the statistics programs SPSS Statistics 19 and AMOS 20 with a focus on linear structural equation modeling. Underlying literature for its application were the guidelines by Weiber and Mühlhaus (2009) and Kline (2011). For the examination of hypotheses $\mathrm{H} 1$ and $\mathrm{H} 2$ the total sample of 211 test persons was used (= named "model H1" and "model H2"). 7 outliers had to be excluded so that 204 test persons actually remained for evaluation. The items were examined with regard to normal distribution. The critical ratio of the skew coefficients partly exceeded the limit value of 2.57 , however, to a moderate extent (Weiber \& Mühlhaus, 2009). The kurtosis coefficient partly exceeded the value 1 . However, the limit value was exceeded only moderately, here, too. The Mardia coefficient describing the multivariate kurtosis has a value of 2.412 which differs significantly from "0" and is therefore admissible (Weiber \& Mühlhaus, 2009). The multivariates concerning the skewness have a value of 1.535 which lies under the limit value of 2.57. In summary, it is safe to assume that the multinormal distribution was transgressed only moderately which allows for using the data. For hypothesis $\mathrm{H} 3$ the random sample was subdivided in order to detect a possible moderating influence of the determinant procrastination. In other words: a multi-group comparison was carried out for which the random sample was divided into two sub-samples (Weiber \& Mühlhaus, 2009). The median of the procrastination values (= 53.0) was used as division criterion. All values larger than 53.0 were excluded from the random sample so that only persons with a below average procrastination disposition remained in the subsample. This subsample consisted of 107 test persons (= named "model H3"). Again, the kurtosis value only in parts exceeded the limit value of 1 moderately, the same is true for the exceedance of the skewness with a limit value of 2.57 (Weiber \& Mühlhaus, 2009). The multivariate concerning the skewness had an absolute value of 1.549 and thus didn't exceed the limit value. The Mardia coefficient describing the multivariate kurtosis had an absolute value of 3.362 and thus differed significantly from " 0 ". Hence, it is safe to assume a moderate transgression of the multinormal distribution here, too, which allows for using the data set (Weiber \& Mühlhaus, 2009). 
For reliability testing the explorative factor analysis (EFA) is used. The examination of the one-dimensionality of the item structure is carried out via measure of sampling adequacy (MSA), commonalities, Kaiser-Meyer-Olkin criterion (KMO) and the Barthlett test (Weiber \& Mühlhaus, 2009). The examination results and the limit values defined by Weiber and Mühlhaus (2009) on the basis of the recommendations of Kaiser and Rice (1974) are listed in the table below (Weiber \& Mühlhaus, 2009). The examination of the total sample (= model $\mathrm{H} 1$ and model H2) is carried out with 204 test persons; the examination of the subsample (= model H3) that is used exclusively for testing hypothesis H3 is carried out with 107 test persons.

Table 2. Criterion Examination of the One-Dimensionality of the Item Structure

\begin{tabular}{lccc}
\hline Criterion & Limit values & Model $\mathrm{H} 1+\mathrm{H} 2$ & Model H3 \\
\hline MSA & $\geq 0.5$ & reached $100 \% *$ & reached $100 \%$ \\
Commonalities & $\geq 0.5$ & $91 \%$ & $66 \%$ \\
KMO criterion & $\geq 0.6$ & 0.657 & 0.677 \\
Barthlett test & significance & 0.000 & 0.000 \\
\hline \multicolumn{2}{l}{ Note. } \\
Mühlhaus, 2009, pp. 107 et sequ.
\end{tabular}

The results show that except for the commonalities in model $\mathrm{H} 3$ the limit values were reached. Deviations were moderate. Thus, no variable was excluded. For the examination of the construct reliability Cronbach's Alpha was used. According to Weiber and Mühlhaus (2009) the limit values vary depending on the author between $\geq 0.9$ and $\geq 0.6$ for explorative research so that for the study at hand a minimum value of $\geq 0.6$ was taken as a basis:

Table 3. Examination of the Construct Reliability

\begin{tabular}{lccc}
\hline Criterion & Limit values & Model H1+H2 & Model H3 \\
\hline Cronbach's Alpha & $\geq 0.6$ & 0.609 & 0.677 \\
\hline
\end{tabular}

This minimum value was reached for both models, which allows for using the data sets. An examination of validity can be omitted as the items are approved and merely contextrelated adaptions were made. The research model is illustrated by an activity diagram. The variables below serve to explain the two activity diagrams: 
Table 4. Explanation of the Variable

\begin{tabular}{lll}
\hline Latent Variable - Exogen & Measure variable/Item & Residual variable \\
\hline EE: Examination Experience & Item $4 \mathrm{U}^{1}, 5$ & e4, e5 \\
AC: Action Control & Item HOM, HOP & e6, e7 \\
& & \\
\hline Latent Variable - Endogenous & Measure variable / Item & Residual variable \\
\hline GI: Goal Intention & Item 9, 12 & e9, e12 \\
II: Implementation Intention & Item 10, 11, 13 & e10, e11, e13 \\
\hline
\end{tabular}

Note. ${ }^{1}$ Item 4 was recoded into item $4 \mathrm{U}$

The models are based on the following assumptions (Weiber \& Mühlhaus, 2009): (1) Variables EE and AC have an explaining character and are thus exogenous; (2) Variables GI and II are influenced by the variables/constructs and are thus endogenous; (3) The measure variables/items item 5, item 9, item 10 and item HOM and HOP are reference indicators or fixed parameters so that the path coefficient here is defined " 1 ". Between the error terms and the corresponding variables a regression weight of 1 was determined. The examination of the models with regard to their identifiability delivered the following results:

Table 5. Identifiability of the Model

\begin{tabular}{lccc}
\hline Criterion & Model H1 & Model H2 & Model H3 \\
\hline Number Sample Moments & 28 & 28 & 28 \\
Number of parameters & 17 & 16 & 17 \\
Degree of freedom & 11 & 12 & 11 \\
Chi square & 31.065 & 48.772 & 17.691 \\
Probability level & 0.001 & 0.000 & 0.089 \\
Matrices & positive & positive & positive \\
\hline
\end{tabular}

The tabular values above show that all three models are identifiable. Even though model H3 slightly misses significance with regard to the probability level it shall be examined further.

\section{Results}

The model evaluation and the interpretation of results are based on the guidelines by Weiber and Mühlhaus (2009). Within the scope of the model evaluation I made a plausibility check. For this purpose, I examined the research models $\mathrm{H} 1$ to $\mathrm{H} 3$ with regard to "implausible parameter estimations" (Weiber \& Mühlhaus, 2009, pp. 159 et seqq.). The results at hand show that in all three models on the basis of the standardized solution no problem cases, i.e. cases where path coefficients, error variances or covariances exceeded the interval -1 to +1 
with regard to the constructs, could be detected. This is an indication for reliable parameter estimation (Weiber \& Mühlhaus, 2009). The inference statistical quality criteria Chi square test, CMIN/DF and Root-Means square error of approximation (RMSEA) deliver the following results:

Table 6. Inference Statistical Quality Criteria

\begin{tabular}{lcccc}
\hline $\begin{array}{l}\text { Criterion }- \\
\text { Default Model }\end{array}$ & Limit Value & Model H1 & Model H2 & Model H3 \\
\hline CMIN/DF & $\leq 2.5$ & 2.8 & 4.0 & \\
RMSEA & $\leq 0.08^{1}$ & 0.09 & 0.12 & 0.07 \\
\hline
\end{tabular}

Note. ${ }^{1}$ Following Brown and Cudeck (as cited in Weiber and Mühlhaus, 2009, p. 162); Limit Values based on the recommendation of Weiber and Mühlhaus, 2009, pp. 160 et seqq.

The RMSEA-values of model H1 show a slight exceedance. Only a RMSEA value of $\geq 0.10$ would be an inacceptable model fit which is not the case. The same applies to the CMIN/DF value. Model H2 shows a significant exceedance with a RMSEA value of 0.12 which suggests an inacceptable model fit. With a value of 4.06 the CMIN/DF value of model $\mathrm{H} 2$, too, significantly exceeds the recommended value of 2.5 (Weiber \& Mühlhaus, 2009). Therefore, I excluded model H2. Model H3 showed no exceedance. The following values apply for the descriptive quality criteria Root Mean Square Residuals (RMR), Goodness of Fit Index (GFI) and Adjusted Goodness of Fit Index (AGFI):

Table 7. Descriptive Quality Criteria

\begin{tabular}{lcccc}
\hline Criterion & Limit value & Model H1 & Model H2 & Model H3 \\
& & & & \\
\hline RMR & as small as possible & 0.052 & 0.358 & 0.062 \\
GFI & $\geq 0.9$ & 0.959 & 0.937 & 0.956 \\
AGFI & $\geq 0.9$ & 0.897 & 0.853 & 0.888 \\
\hline
\end{tabular}

Note. Limit Values based on the recommendation of Weiber and Mühlhaus, 2009, pp. 164 et seqq.

The results show that the limit values were observed by the models $\mathrm{H} 1$ and $\mathrm{H} 3$, whereas model $\mathrm{H} 2$ exceeds the RMR value. For the incremental fit measures the normed fit index (NFI), the comparative fit index (CFI) and the incremental fit index (IFI) were used with the following standard values: 
Table 8. Incremental Fit Measures

\begin{tabular}{lcccc}
\hline Criterion & Limit value & Model H1 & Model H2 & Model H3 \\
& & & & \\
\hline Normed fit index (NFI) & $\geq 0.9$ & 0.840 & 0.738 & 0.869 \\
Comparative fit index (CFI) & $\geq 0.9$ & 0.890 & 0.789 & 0.946 \\
Incremental fit index (IFI) & $\geq 0.9$ & 0.884 & 0.777 & 0.941 \\
\hline
\end{tabular}

Note. Limit Values based on the recommendation of Weiber and Mühlhaus, 2009, pp. 170 et seqq.

The fit measures, too, show that the limit values were observed by the models H1 and $\mathrm{H} 3$, whereas model $\mathrm{H} 2$ is below the limit values. Based on the present values for the model evaluation I can now perform an interpretation of results. As a first step I will carry out a plausibility check and a parameter evaluation of the model relations between goal intention (GI), implementation intention (II) and examination experience (EE). This was done by using the critical ratio values (C.R. $\geq 1.96$ ) and the probability of error value $\mathrm{P}$ (Weiber \& Mühlhaus, 2009). The following values were detected for model H1:

Table 9. Verification of Hypothesis H1

\begin{tabular}{lll}
\hline $\begin{array}{l}\text { Hypotheses - } \\
\text { Model H1 }\end{array}$ & C.R. & P \\
\hline EE - GI & 0.681 & 0.496 \\
EE - II & 2.125 & 0.034 \\
GI - II & 3.140 & 0.002 \\
\hline
\end{tabular}

The results show that the model relations EE - II and GI - II are approvable whereas EE - GI is unacceptable. This can be illustrated by the activity diagram below: 


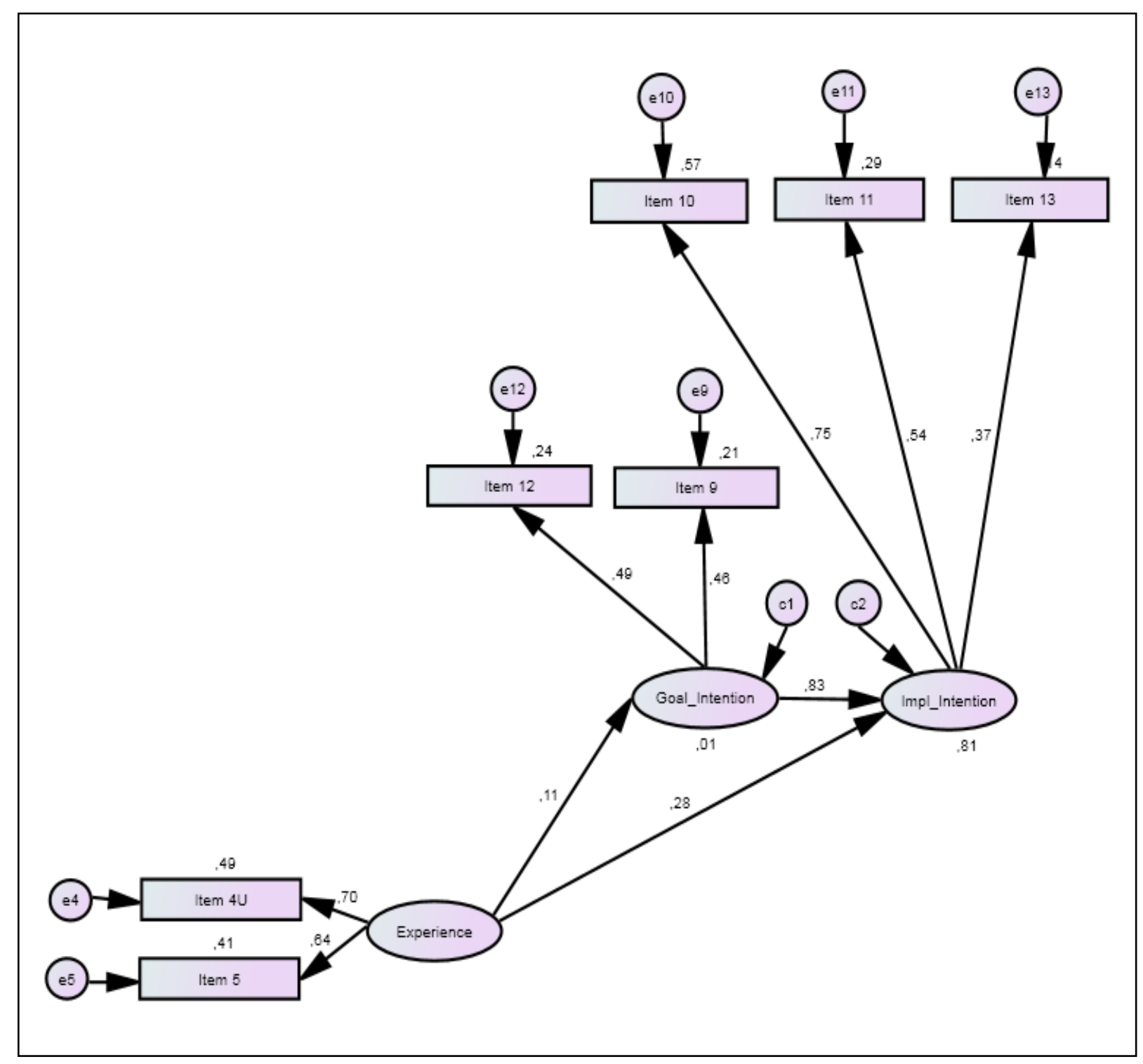

Figure 3. Standard estimates - Research Model H1 with 204 test persons

A detailed examination of the causal hypotheses for model $\mathrm{H} 1$ delivered the following results (Weiber \& Mühlhaus, 2009):

- The signs of the path coefficients for the relation between examination experience (EE) and goal intention (GI) and/or implementation intention (II) show a positive value, i.e. the model estimation coincides with the hypothetical model relation as described in hypothesis $\mathrm{H} 1$. 
- As for the standardized regression weights or path coefficients concerning EE - GI and EE - II with a value of 0.11 and 0.28 only the latter reaches a significant value of $>0.2$ (Weiber \& Mühlhaus, 2009). Thus, only the relation between EE and II has to be regarded as significant. With 0.83 , the relation GI - II reaches a high value which is in line with Gollwitzer (1999) who stated that implementation intention follows goal intention.

- The squared multiple correlation (SMC) shows that only 1 percent of the variance concerning goal intention can be explained by examination experience (EE). Concerning implementation intention, the SMC value was at 0.81 , with path coefficients of 0.83 and 0.28 showing that, next to GI, EE delivers a substantial explanatory contribution.

I identified the research model $\mathrm{H} 2$ as unacceptable and therefore I will not illustrate it in detail. However, a short description of the results shall be given, stating which influence action control (AC) as defined by Kuhl $(1981,1982,1994)$ would have had on implementation intention (II) and goal intention (GI) according to the model estimation, had it been applicable.

Table 10. Verification of Hypothesis $\mathrm{H} 2$

\begin{tabular}{lccc}
\hline $\begin{array}{l}\text { Hypotheses - } \\
\text { Model H2 }\end{array}$ & C.R. & P & $\begin{array}{c}\text { Path coeffi- } \\
\text { cient }\end{array}$ \\
\hline AC - GI & 1.888 & 0.059 & 0.36 \\
AC - II & 1.295 & 0.195 & 0.23 \\
GI - II & 2.774 & 0.006 & 0.75 \\
\hline
\end{tabular}

The critical ratio value (C.R. $\geq 1.96)$ was reached only for the GI - II relation (Weiber \& Mühlhaus, 2009). All other values would have been unacceptable, which confirms the assumption of a general inadmissibility of the model. Research Model H3 delivered the following results with regard to plausibility check and parameter evaluation:

Table 11. Verification of Hypothesis H3

\begin{tabular}{lcc}
\hline $\begin{array}{l}\text { Hypotheses - } \\
\text { Modell H3 }\end{array}$ & C.R. & P \\
\hline EE - GI & 0.068 & 0.946 \\
EE - II & 2.666 & 0.008 \\
GI - II & 2.405 & 0.016 \\
\hline
\end{tabular}


The results at hand show that taking into consideration the C.R. value only the relations EE - II and GI - II are admissible. The activity diagram below illustrates the matter:

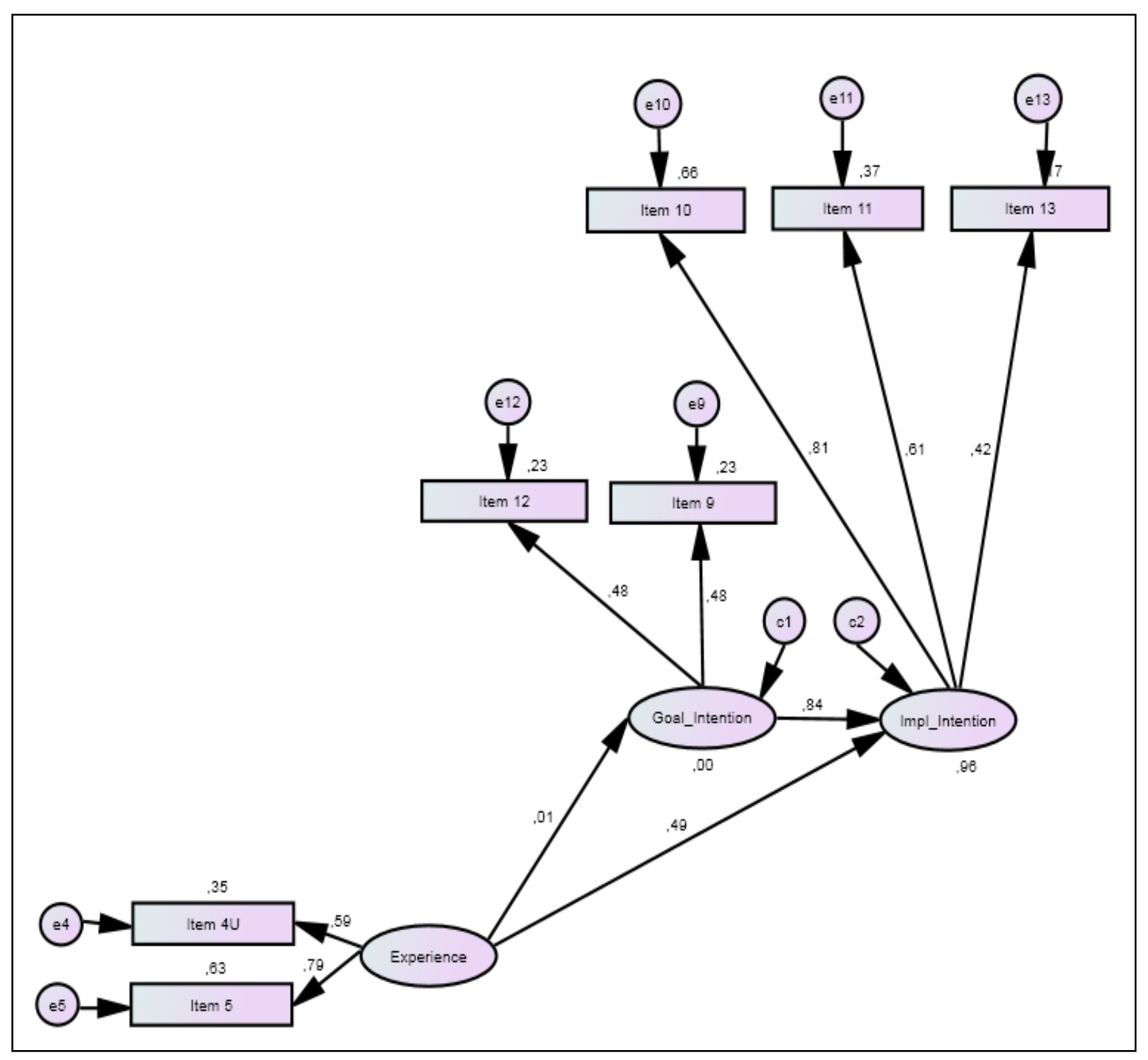

Figure 4. Standard Estimates - Research Model H3 with 107 test persons

The detailed examination of the causal hypotheses for model $\mathrm{H} 1$ delivered the following results (Weiber \& Mühlhaus, 2009):

- The signs of the path coefficients for the relation between examination experience (EE) and goal intention (GI) and/or implementation intention (II) show positive values, i.e. the model estimation coincides with the hypothetical model relation as described in hypothesis $\mathrm{H} 3$. 
- As for the standardized regression weights or path coefficients concerning EE - GI and EE - II with a value of 0.01 and 0.49 , only the latter reaches a significant value of $>0.2$ (Weiber \& Mühlhaus, 2009). As expected, the relation GI - II reaches a high value with 0.84 which is in line with Gollwitzer (1999).

- The squared multiple correlation (SMC) shows that 0 percent of the variance concerning goal intention can be explained by examination experience (EE). Concerning implementation intention, the SMC value was at 0.96 , with a path coefficient of 0.49 showing that EE, too, delivers a substantial explanatory contribution.

\section{Discussion}

On the basis of the results mentioned above, I came to the following conclusions for hypotheses $\mathrm{H} 1$ to $\mathrm{H} 3$. The positive influence of examination experience (EE) in the sense of "knowledge/skills" on goal intention (GI) and implementation intention (II) that was expected according to hypothesis $\mathrm{H} 1$ with regard to the context of university students' exam revision is confirmed. The admissibility and significance of the model estimation is confirmed likewise. However, it was noticeable that the relation between EE and GI was neither substantial nor significant. Only the relation between EE and II was substantial and significant which could be interpreted as a continuation of the approach of Ziegelmann, Luszczynska, Lippke and Schwarzer (2007). According to this, repeated behavior (routine) - in other words: experience with regard to behavior - leads to an increase of significance of implementation intention with regard to behavior implementation, whereas goal intention loses significance. Ziegelmann et al. (2007) underlined "that it may be implementation intentions rather than goal intentions that have an impact on behavior, even as behavior becomes more routinized. It is possible that, at the stage when behavior becomes routine, planning still predicts exercise behavior" (p. 100), in other words: experience has a strong effect on II and a weaker effect on GI. Thus, I concluded that the strict denial of any influence of experience in general on intention as described by Ajzen (2005) applies to goal intention (Ajzen, 2005, p. 136) but not to implementation intention. Attitude (ATT), social norm (SN) and perceived behavioral control (PBC) are approved determinants for goal intention which influence implementation intention as successive intention according to Gollwitzer (1999), as confirmed by the results of the study at hand. However, from the author's point of view, intention as such is influenced to a significant, substantial extent by context-related experience, too. This perception is in accordance with a 
number of studies listed in the literature review that repeatedly document the relevance of experience in its different forms (e.g. past behavior, past experience, habits). With respect to the intensity of the influence, I assume that the repetitiveness (Ziegelmann et al., 2007) of behavior plays an important role, as already mentioned in various publications. However, here is need for further research. In summary, hypothesis 1 can be regarded as confirmed.

Hypothesis 2 deals with the question, if the construct action control developed by Kuhl $(1981,1982,1994)$ has a comparable effect on GI and II as the construct experience. Unfortunately, no conclusions can be drawn due to the lacking admissibility of research model $\mathrm{H} 2$. I would like to point out that these facts, too, can be interpreted as a tendency that action control (AC) in connection with the HOM and HOP values as defined by Kuhl (1981, 1982, 1994) is a difficult-to-handle determinant for intention. Similar results could be found with regard to the state orientation by Papantoniou, Moraitou, Katsadima and Dinou (2010). Furthermore, the conclusion drawn by van Hooft et al. (2005) that "the proposed moderating roles of action-state orientation ... were not supported“" (p. 238) is confirmed by the results of the study at hand.

Hypothesis 3 deals with the question if the construct procrastination acts as moderator between experience and intention. I assume that examination experience has a positive influence on goal and implementation intention. However, as far as goal intention is concerned, this influence is neither substantial nor significant. With regard to implementation intention, in contrast, there is a substantial, significant influence. Insofar, the results of hypothesis 3 are consistent with the results of hypothesis 1 . The question if procrastination had an intensifying influence on these relations can be answered by regarding the path coefficients. Compared to model $\mathrm{H} 1$ the path coefficient increased from 0.28 to 0.49 in model H3. Thus, hypothesis $\mathrm{H} 3$ stating that the determinant procrastination has a moderating impact on examination experience (EE) is confirmed. Therefore, I conclude that procrastination is a context-related experience and thus should be assigned to the construct experience. However, this result is contradictory to the findings that "the proposed moderating roles of ... trait procrastination were not supported" (van Hooft et al, 2005, p. 238). Concerning this matter, it should be noted that one reason for the deviation of results is that the questions concerning procrastination were adapted by the author with regard to the context. In other words: it is, for example, possible that a person shows a general procrastination tendency that doesn't apply for certain contexts. Another reason for deviation could be that van Hooft et al. (2005) measured procrastination 
on the 9-items scale defined by Lay (1986), whereas this paper is based on Aitken's (1982) scale.

\section{Conclusion}

Based on the results / discussion some interesting conclusions concerning higher education can be drawn from the study: (1) Examination experience (EE) influences university students' exam revision to an extent that exceeds the influence that is expected by the TPB model, which necessitates a general reassessment of examination experience in the field of higher education; (2) the development of implementation intention (II) is promoted by goal intention (GI) as well as by examination experience (EE) which suggests a dual approach for a successful support of students' exam revision in the field of higher education. In other words: turning away from the unilateral focus on goal intention (GI) is reasonable; (3) resolutions in the sense of goal intention are not enforced significantly by examination experience. In fact, examination experience primarily takes effect on implementation intention which makes it advisable to convey methodological competence to the students in terms of exam revision at an early stage. Early experience significantly promotes the development of implementation intention; (4) examination experience can have a positive influence on procrastination behavior which also confirms that - next to goal intention - separate importance with regard to the development of implementation intention has to be attached to repetitive behavior (Ziegelmann et al., 2007). This underlines the demand for an enforced transfer of methodological competence to students in terms of exam revision; (5) a lack of methodological skills or examination experience due to unequal academic qualification can amongst other things be decisive for study success which makes it recommendable to cover these subjects in electives or, even better, in compulsory courses in higher education institutions.

\section{Limitations}

The study is subject to the following limitations: (1) The random sample in model H1 and $\mathrm{H} 2$ consisting of 204 students was relatively small and should be enlarged in future studies. This applies even more to model H3 consisting of only 107 test persons; (2) The items for detecting experience should be amplified in order to be able to identify this construct more distinctly. In this connection, I recommend to examine different levels of experience separately. An amplification of the items for the detection of goal and implementation intention is helpful for the improvement of the quality of the model estimation; (3) Furthermore, I recommend a comparative examination of the different item batteries of Lay (1986) and Aitken 
(1982) for the detection of procrastination; (4) Another approach to examine the relevance of experience in the context of university student's exam revision is taking into account the number of semesters. I suggest to examine if graduate students with usually more examination experience show different behaviors with regard to exam preparation than younger students; (5) For future studies I propose to include besides intention also the actual exam behavior. In the framework of the study a feedback form was made available. However, there were 32 returns only so that no evaluation was made; (6) It has to be analyzed if the time and effort required for a an enforced transfer of methodological skills with regard to students' exam revision has a beneficial impact on examination results and/or other professional skills.

\section{References}

Adriaanse, M., Gollwitzer, P., Ridder, D., de Wit, J., \& Kroese, F. (2011). Breaking Habits With Implementation Intention: A Test of Underlying Processes. Personality and Social Psychology Bulletin, 37, 502-513. doi: 10.1177/0146167211399102

Aitken, M. E. (1982). A Personality Profile of the College Student Procrastinator (Doctoral Dissertation, University of Pittsburgh, 1982); Dissertation Abstracts International, 43.

Ajzen, I. (1985). From Intention to action: A Theory of Planned Behavior. In Kuhl and Beckmann (Eds.), Action Control: From Cognition to Behavior (pp, 11-39). Berlin: Springer Verlag

Ajzen, I. (1991). The Theory of Planned Behavior. Organizational Behavior and Human Decision Processes, 179-191.doi: 10.1016/0749-5978(91)90020-T

Ajzen I. (2005). Attitudes, Personality and Behavior. Great Britain: Open University Press.

Bagozzi, R., Baumgartner, H., \& Yi, Y. (1992). State versus Action Orientation and the Theory of Reasoned Action: An Application to Coupon Usage. Journal of Consumer Research, 18, 505-518. doi: 0093-5301/92/1804-0008

Brandstätter, V., Lengfelder, A., \& Gollwitzer, P. (2001). Implementation Intentions and Efficient Action Initiation. Journal of Personality and Social Psychology, 81, 946-960. doi: 10.1037/0022-3514.81.5.946

Brunstein, J. (2001). Personal Goals and Action Versus State Orientation: Who Builds a Commitment to Realistic and Need-Congruent Goals? Zeitschrift für Differentielle und Diagnostische Psychologie, 22, 1-12. doi: 10.1024//0170-1789.22.1.1

Cambridge University (2012). Online Dictionary. Retrieved July 25, 2012, from 
http://dictionary.cambridge.org/dictionary/ british/experience

Chu, A., \& Choi, J. (2005). Rethinking Procrastination: Positive Effects of „Active“ Procrastination Behavior on Attitudes and Performance. The Journal of Social Psychology, 145, 245-264. doi: 10.3200/SOCP.145.3.245-264

Clariana, M., Gotzens, C., Badia, M., \& Cladellas, R. (2012). Procrastination and cheating from secondary school to university. Electronical Journal of Research in Educational Psychology, 27, 737-754. ISSN: 1696-2095

Coté, F., Gagon, J., Kouffé Houme, P., Abdeljelil, A., \& Gagon, M. (2012). Using the Theory of Planned Behaviour to predict nurses' intention to integrate research evidence into clinical decision-making. Journal of Advanced Nursing. doi: 10.1111/j.13652648.2011.05922.x

de Bruin, M., Sheeran, P., Kok, G., Hiemistra, A., Prins, J., Hospers, H., \& van Breukelen, G. (2012). Self-Regulatory Processes Mediate the Intention-Behavior Relation for Adherence and Exercise Behaviors. Health Psychology, 5. doi: 10.1037/a0027425

Dewitte, S., \& Schouwenburg, H. (2002). Procrastination, Temptations, and Incentives: The Struggle between the Present and the Future in Procrastinators and the Punctual. European Journal of Personality, 16, 469-489. doi: 10.1002/per.461

Fischbein, M., \& Ajzen, I. (1975). Belief, Attitude, Intention, and Behavior. An Introduction to Theory and Research. United States: Addison-Wesley

Gollwitzer, P.M. (1993). Goal Achievement: The Role of Intentions. European Review of Social Psychology, 4, 141-185. doi: 10.1080/14792779343000059

Gollwitzer, P. M. (1999). Implementation Intentions: Strong effects of simple plans. American Psychologist, 54, 493 - 503. doi: 10.1037/0003-066X.54.7.493

Hrisos, S., Eccles, M., Johnston, M., Francis, J., Kaner,E.F.S., Steen, N., \& Grimshaw, J. (2008). Developing the Content of Two Behavioural interventions: Using Theory-based Interventions to Promote GP Management of Upper Respiratory Tract Infection Without Prescribing Antibiotics \#1. BMC Health Services Research, 8, 1-8

Kaiser, H. F., \& Rice, J. (1974). Little Jiffy, Mark Iv. Educational and Psychological Measurement, 34 (1), 111-117. doi: 10.1177/001316447403400115

Kline, R. B. (2011). Principles and practice of structural equation modelling. New York: Guilford.

Kuhl, J. (1981). Motivational and Functional Helplessness: effect of state versus action orientation. Journal of Personality and Social Psychology, 40, 155-170. doi: 10.1037/0022- 
3514.40 .1 .155

Kuhl, J. (1982). Action vs State Orientation as a Mediator between Motivation and Action. Cognitive and Motivational Aspects of Action. In W. Hacker (Ed.), Cognitive and motivational aspects of action. Amsterdam: North-Holland.

Kuhl, J. (1994). A Theory of Action and State orientations. In Kuhl, J./Beckmann, J. (Eds.), Volition and Personality: Action versus State Orientation (pp. 6-46), Göttingen: Hogrefe-Verlag.

Kuhl, J., \& Beckmann, J. (1985). Action Control: From Cognition to Behavior. Berlin: Springer Verlag

Lay, C.H. (1986). At Last, My Research Article on Procrastination. Journal of Research in Personality, 20(4), 474-495. doi: 10.1016/0092-6566(86)90127-3

Mannetti, L., Pierro, A., Higgins, E., \& Kruglanski, A. (2012). Maintaining Physical Exercise: How Locomotion Mode Moderates the Full Attitude-Intention-Behavior Relation. Basic and Applied Social Psychology, 34. doi: 10.1080/01973533.2012.693442

Montalvo, F. T., \& Torres, M. C. G. (2004). Self-Regulated Learning: Current and Future Directions. Electronical Journal of Research in Educational Psychology, 2, 1-34. ISSN: 1696-2095

Norman, P., Sheeran, P., \& Orbell, S. (2003). Does State Versus Action Orientation Moderate the Intention-Behavior Relationship? Journal of Applied Social Psychology, 33, 536553. doi: 10.1111/j.1559-1816.2003.tb01911.x

Papantoniou, G., Moraitou, D., Katsadima, E., \& Dinou, M. (2010). Action control and dispositional hope: An examination of their effect on self-regulated learning. Electronical Journal of Research in Educational Psychology, 20, 5-32. ISSN: 1696-2095

Princeton University (2012). The McGraw Center for Teaching \& Learning. Retrieved October 25, 2012, from http://www.princeton.edu/mcgraw/library/for-students/avoidingprocrastination/procrastination.pdf

Rhodes, R., \& Courneya, K. (2003). Modelling the theory of planned behaviour and past behavior. Psychology, Health \& Medicine, 8(1), 57-69. doi: 10.1080/1354850021000059269

Rhodes, R., Brown, S., \& McIntyre, C. (2006). Integrating the perceived neighbourhood environment and the theory of planned behaviour when predicting walking in a Canadian adult sample. American Journal of Health Promotion, 21, 110-8. PMID: 17152250

Rhodes, R., \& Dickau, L. (2012). Moderators of the intention-behaviour relationship in the physical activity domain: a systematic review. British Journal of Sports Medicine. doi: 
10.1136/bjsports-2011-090411

Rist, F., Engberding, M., Patzelt, J., \& Beißner, J. (2006). Aber morgen fange ich richtig an! Zeitschrift Personalführung, 6, 64-78.

Sheeran, P., Orbell, S., \& Trafimow, D. (1999). Does the Temporal Stability of Behavioural Intentions Moderate Intention-Behaviour and Past Behaviour-Future Behaviour Relations? Personality and Social Psychology Bulletin, 25(6), 724-730. doi: $10.1177 / 0146167299025006007$

Sheeran, P., Webb, T., \& Gollwitzer, P. (2005). The Interplay Between Goal Intentions and Implementation Intentions. Personality and Social Psychology Bulletin, 31, 87-98. doi: $10.1177 / 0146167204271308$

Sniehotta, F., Nagy, G., Scholz, U., \& Schwarzer, R. (2006). The role of action control in implementing intentions during the first weeks of behavior change. British Journal of Social Psychology, 45, 87-106. doi: 10.1348/014466605x62460

Sommer, L. (2010). Prokrastination. Unpublished manuscript. Department of Business Administration and Engineering, Albstadt-Sigmaringen University, Albstadt, Germany.

Sommer, L. (2011). The Theory of Planned Behaviour and the Impact of Past Behaviour. International Business \& Economics Research Journal, 10(1), 91 - 110

Sommer, L., \& Haug, M. (2012). What Influences Implementation Intentions in an Academic Learning Context - The roles of Goal Intentions, Procrastination, and Experience. International Journal of Higher Education, 1, 32-61, doi: 10.5430/ijhe.v1n1p32

Universität Zürich (2010). Bereich Psychologie. Retrieved July 28, 2012, from http://www.psychologie.uzh.ch/fachrichtungen/motivation/Studium/lehre/alt/ws0506/me thoden IWS0506/hakemp90.pdf

van Hooft, E., Born, M., Taris, T., van der Flier, H., \& Blonk, R. (2005). Bridging the gap between intentions and behavior: Implementation intentions, action control, and procrastination. Journal of Vocational Behavior, 66, 238-256. doi: 10.1016/j.jvb.2004.10.003

Weiber, R., \& Mühlhaus, D. (2009). Strukturgleichungsmodellierung - Eine anwendungsorientierte Einführung in die Kausalanalyse mit Hilfe von AMOS, SmartPLS und SPSS. Berlin: Springer Verlag.

Ziegelmann, J., Luszczynska, A., Lippke, S., \& Schwarzer, R. (2007). Are Goal Intentions or Implementation Intentions Better Predictors of Health Behavior? A Longitudinal Study in Orthopedic Rehabilitation. American Psychological Association, 52, 97-102. doi: $10.1037 / 0090-5550.52 .1 .97$ 


\section{Appendices}

Questionnaire

Item-Numbers Questions

A. General and additional part ${ }^{1}$

Item 1: Age

Item 3: Course of studies

Item 5: Type of school / school board

Item 7: Type of exam revision
Item 2: Gender

Item 4: Type of school leaving qualification

Item 6: Experience

Item 8: Experience concerning revision

B. Special part - Intention ${ }^{1}$

Item 9 : $\quad$ I intend to prepare thoroughly for the subject/the examination.

Item 10: I have a detailed plan stating when, how and to which extent I have to prepare for the subject/examination.

Item 11: I have a detailed plan under which circumstances I will alter my plan or make up for delay.

Item 12: $\quad$ For the ongoing winter semester I can say with regard to exam revision: I have been preparing for this subject since mid-November!

Item 13: $\quad$ For the ongoing winter semester I can say with regard to exam revision: I have plans since mid-November stating when, what and how to prepare!

Item 14 - 21: Questions concerning the Theory of Planned Behavior - not part of the study at hand!

C. Special part - Procrastination ${ }^{1}$

Item 22 - Item 40 based on Aitken (1982); see also Rist et al (2006)

D. Special part - Action Control ${ }^{1}$

Items based on HAKEMP 90 (University Zürich, 2010)

Note. 'Adapted from Sommer and Haug (2012), based on Sheeran et al (2005); Rhodes \& Courneya (2003); Rhodes et al (2006); Gollwitzer (1999); Hrisos et al (2008); Ajzen (2005); Universität Zürich (2010); Aitken (1982); HAKEMP 90 (University Zürich, 2010). A more detailed list of the sources can be found in the method section.

\section{Author Note}

The manuscript is partly based on data which I have used in a previously published article: Sommer, L., \& Haug, M. (2012). What Influences Implementation Intentions in an Academic Learning Context - The roles of Goal Intentions, Procrastination, and Experience. International Journal of Higher Education, 1, 32-61, doi: 10.5430/ijhe.v1n1p32 